\title{
The Improvement of Students' Scientific Literacy based on Biology Concept Teaching
}

\author{
1 Wang Wei 2 Wu Xia \\ College of Life Science, Sichuan Normal University \\ Sichuan Chengdu 610101 \\ 1 Wangwei (Sichuan Normal University, College of Life Science, Chengdu, Sichuan, 610101, China) \\ 2 Wuxia (Sichuan Normal University, College of Life Science, Chengdu, Sichuan, 610101, China)
}

Fund project: Sichuan Normal University Youth Training Project: High school biology important concept scientific concept investigation and study in Sichuan Province, project number: 16 QP01

\begin{abstract}
One of the basic tasks of biology concept teaching is to improve students' scientific literacy. Improve teaching methods and optimize biology course teaching way by using the basic features of biology teaching, combining with the new education idea. This can make students form correct scientific attitude, research method and the concept of life science, and establish their scientific world view in learning biology.
\end{abstract}

\section{Key words: Biology; Teaching; Scientific literacy; Biological literacy}

In the 21st century, with rapid science development, the era of life science has come. The cultivation of students' scientific literacy is the need of times development for education during this period. Biology concept teaching goal is to cultivate students' science inquiry ability and scientific literacy, and the targets at the same time also are the basic goal of biology teaching at home and abroad. According to the new standard for Biology Course Standard, biological science literacy is the basic purpose and basic idea in biology concept education, and at the same time, the new standard also mentions "scientific literacy is a scientific inquiry ability and scientific concept required for personal decision and production practice, economic activity, social activities, which includes the understanding of the relationship between society, technology and science [1]. And the understanding of the nature of science also includes the correct scientific attitude and scientific world outlook, the outlook on life and values, etc." Every biology teacher should consciously cultivate every student's scientific literacy in biology concept teaching. Improve students' scientific literacy is a research topic every biology education worker should study, and it is the important task and the core target of each school in formulating biology teaching.

\section{THE MEANING OF SCIENTIFIC LITERACY}

Scientific literacy refers to a person's scientific values, scientific spirit, scientific attitude, the science knowledge mastered and scientific behavior and thinking habits, etc. In particular, it shows in some of the following aspects: with scientific literacy, a person can find some problems in daily life, and be able to solve these problems due to their curiosity; people have scientific literacy are able to explain and describe some imagination in daily life; people have scientific literacy can make their own evaluation on some popular science magazines or books have the ability to participate in some social discussion; people have scientific literacy have knowledge about a country or region's basic scientific problems on survival basis, and can make their own views on these problems [2]. People have scientific literacy can determine the reliability of information according to the sources of information and relevant data; people have scientific literacy can put forward their views on the object and provide large amounts of data and theory to support their ideas. Scientific literacy is the scientific knowledge and scientific research ability a citizen should have to participate in social activities. It is a reflection of a person values and emotional attitude. In education, improve each students' scientific literacy is a basic teaching target for each education worker. 


\section{WAYS TO IMPROVE STUDENTS’ SCIENTIFIC LITERACY OF IN BIOLOGY}

\section{A. Penetrate the forefront information of biological science and technology and cultivate students' science consciousness}

Biological education workers should concern about science information in daily life, and associate the scientific biological information with the key points in biology classroom, so that the new development of science and the biological basic knowledge in teaching material are related. This triggers students' attention and thinking activity in science. This has an important role in training students' attention to science and can cultivate students' scientific literacy. For example, in learning "the material basis for genetic" class, biology teacher can associate genetic engineering and other scientific frontiers knowledge into the classroom. The forefront scientific knowledge introduction can not only open students' scientific perspective, also can arouse students' scientific curiosity and desire for knowledge in biological science. This is to cultivate students' consciousness of science, and it can help students' better understanding of the biological materials.

\section{B. Cultivate the students' scientific spirit through scientific case education}

The same basic ways of thinking, mental state, way of thinking, and scientific spirit throughout various scientific activities are scientific nature, which is also some of the basic ideas or thoughts embodying in much scientific knowledge. In the new standard, one thought deserves emphasize is that "pay attention to the study of biology" [3]. This clears that biology concept education is a very important way to improve students' scientific literacy, and is precious resources shaping the students' scientific literacy and scientific spirit. In biology teaching activity, biological pharmaceutical education workers can give full play to the biology effect on improving students' scientific literacy. They can not only use biology "story" to cultivate students' interest in biological learning, but also cultivate the students' scientific spirit and values by telling some famous biologist biography in biology textbooks. In the process of biology teaching, biological education workers can let the students have specific understanding about the biology knowledge forming process by recreating some classic examples and the related analysis logic. In the understanding of these instances, students can have a sober understanding on scientists' way of thinking concept and biology principle. The reproduce of the teaching process scene, the boring biology knowledge, combined with the instances, is easier to understand, and can help students learn scientific way of thinking and cultivate the students' scientific spirit.

\section{Apply inquiry teaching and cultivate students' scientific research methods}

Biology is a science and it is based on experimental science, so much of the biology knowledge is suited to be acquired by students through their autonomous learning and research way of learning. Students' inquiry learning not only obtains biological knowledge more easily and firmly, but also in the same time of independent exploration of the biological knowledge, instills biological scientists' scientific research methods and scientific way of thinking. In the process of biology teaching, the teacher must first provide students with a scientific and feasible learning environment, help students to ask questions, and help students to make reasonable assumptions for their questions, provides an opportunity for students' whimsical ideas, and let the student's curiosity and desire to explore and get great satisfaction. Ask questions and make assumptions, biology teacher should guide and help students to collect information about questions and encourage students' thinking from multiple channels. At the same time, teachers should also establish friendly communication with students and encourage students to illustrate their opinions and views. This can help the students to find and fix problems in their own assumptions, and establish a scientific and correct assumption [4]. Teachers should help students learn to ask questions and analyze problems, and help students improve the ability to solve problems independently, and cultivate the students' scientific research methods.

\section{Use biological experiments and train the students' rigorous scientific attitude}

Because the basis of biology is experiment, the development of biology and the development of research methods are closely related. Biological can develop from the early descriptive subject into today's experimental science is because with the development of economy and the progress of science, experiment technology and methods have great development. Biological science development to today's levels cannot be separated from the experiment of biologists. Likewise, students want to have a clear understanding of biology and have a solid grasp of knowledge biological basis, it is necessary to do biological experiments. When student carry on the experiment, the teacher should have a strict 
requirement to the students' experiment report, or this will have a serious impact on the whole experiment results, and teacher should have scientific requirements for the essay after the experiment [5]: before the experiment, students should write about the experimental steps design according to the preliminary grasp of the experiment content; In the process of experiment, the students should be in strict accordance with the correct and scientific experimental steps of the experiment, the experimental records must according to the experiment phenomenon of various analysis and for experimental results, make scientific explanation for the experiment phenomenon; at the end of the experiment, summarize the experimental process and supplement experiment steps designed, and analyze and explain the result of the experiment. If in the process of experiment, some phenomenon appeared which not the same as the experiment expectation is, record the numbers and do not randomly transform experiment result. Such strict requirements in experiments can exercise students' experimental ability, and make students form scientific rigorous experimental concept, strive for scientific research methods, and motivate students write their opinion of experiment as well as the improved method of the deficiency in the experiment report, which can help students improve their rigorous scientific attitude and scientific innovation ability.

\section{E. Dig teaching material content and cultivate students' emotional attitude and values}

In the process of biology teaching, there is a well of education content worth teaching, so biological education workers should make in-depth knowledge mining for the contents in the textbooks, and, extensively collect biological science content, let biology knowledge and experimental explore reflect the biology value emotion and scientific thought. Emotional attitude can reflect the scientific values of biology. But the most important still is the teachers fully excavate the knowledge content in biology teaching, and help students to build up scientific and correct life values and social values.

\section{F. Strengthen the infiltration of interdisciplinary knowledge and form scientific world outlook}

Biology research content is a more advanced form of material objects sport development than chemistry, physics and other discipline. This complicated and delicate process of material movement not only reflects the essence of life movement development, but also studies the nonliving variables' influence and constraints on this kind of material movement. So biology is a comprehensive discipline, which not only has its disciplinary characteristic, also involves judgment standard to a certain degree in the disciplines such as chemistry, physics. For example in plane live solution frogs and ridge frog reflex experiments, we need some physical equipment and some chemicals; Also in soybean hybrid experiments, for example, we should not only control soybean seeds, but control nonliving factors such as fertilizer, temperature, soil quality for planting soybean seeds. The comprehensive characteristics of biology will cultivate the comprehensive ability of students, such as observing ability, thinking ability, operation ability and so on, and help students form scientific and systematic view of the world.

\section{CONCLUSION}

Using biology concept teaching to cultivate students' scientific literacy has more superiority than other subjects. In today's developed science and technology and higher levels of economic and social environment, the development of biology is becoming more and more important. Currently, the basic biology teaching goal is to improve students' scientific literacy, and cultivate students' scientific learning method and scientific way of thinking through the basic biology textbook knowledge study. Through biological experiments, cultivate students' scientific inquiry method and rigorous scientific attitude. In a nutshell, biology learning is a valuable resource and carrier to improve students' scientific literacy. Biology concept teaching can achieve students' emotional attitude, research ability, and knowledge and values improvement and finally promote the improvement of students' scientific literacy.

\section{REFERENCES}

[1] Wang Xiuli. Cultivate students' scientific literacy by using biology teaching material resources [J]. Journal of Biology Teaching, 2015, (9) : 37-38.

[2] Zhao Yulan. A way to improve students' scientific literacy in biology experimental teaching [J]. Journal of Biology Teaching, 2009 (10) : 21-22.

[3] Wang Zhong. High school biology curriculum goal is to improve citizens' scientific literacy---- "Biology" new Sue textbook 
introduction for high schools [J]. Journal of Biology, 2006, 9 (4) : 22-24.

[4] Li Chuanyin. Reform of biology experimental teaching to improve students' scientific literacy [J]. Journal of biology, 2004, 33 (3) 6:42-43.

[5] Jiang Jianping. Emphasis on biology experiment teaching to cultivate students' biological science literacy [J]. Journal of Biology Teaching, 2013, 38 (9): 43-44.

Author introduction: 